\title{
ENDOGENOUS ECONOMIC VOTING: EVIDENCE FROM THE 1997 BRITISH ELECTION
}

\author{
Christopher J. Anderson \\ Binghamton University, SUNY \\ Binghamton, New York, USA \\ Silvia M. Mendes \\ Universidade do Minho \\ Braga, Portugal \\ Yuliya V. Tverdova \\ Binghamton University, SUNY \\ Binghamton, New York, USA
}

\begin{abstract}
Using panel surveys conducted in Great Britain before and after the 1997 general election, we examine the relationship between voting behavior and post-election economic perceptions. Drawing on psychological theories of attitude formation, we argue that those who voted for Labour and the Liberal Democrats perceived the past state of the British economy under the Tory government more negatively than they had prior to casting their ballot in the 1997 election. Similarly, we posit that Labour supporters would view the future state of the national economy under Labour more positively than they had before the election. This indicates that, contrary to many assumptions in the economic voting literature, voting behavior influences evaluations of the economy as voters seek to reduce inconsistencies between their vote choice and evaluations of the economy by bringing their attitudes in line with the vote they cast in the election. It also means that voters' post-election economic perceptions are, at least in part, influenced by and thus endogenous to their vote choice. This finding has two major implications: First, cross-sectional models of economic voting are likely to overestimate the effect of economic perceptions on the vote. Second, the endogeneity of economic perceptions may compromise the quality of economic voting as a mechanism for democratic accountability.
\end{abstract}

Acknowledgments:

This research was conducted in part with the help of NSF Grant SES-9818525 to Chris Anderson. The data come from ICPSR Study No.2616. The original collector of the data, ICPSR, and the relevant funding agency bear no responsibility for uses of this collection or for interpretations or inferences based upon such uses. The data were analyzed with the help of the STATA econometric software. We would like to thank Haklin Kim and Elena Sandovici for their help with data and Andrew LoTempio and Ajla Dzudza for their helpful comments. Many thanks also to Kathleen O'Connor for her invaluable advice.

Address all correspondence to:

Christopher J. Anderson

Department of Political Science

Center on Democratic Performance

Binghamton University, SUNY

Binghamton, New York 13902-6000, USA

(607) 777-2462 [voice] -2675 [fax]

christopher.anderson@binghamton.edu (email) 


\title{
ENDOGENOUS ECONOMIC VOTING: EVIDENCE FROM THE 1997 BRITISH ELECTION
}

\begin{abstract}
Using panel surveys conducted in Great Britain before and after the 1997 general election, we examine the relationship between voting behavior and post-election economic perceptions. Drawing on psychological theories of attitude formation, we argue that those who voted for Labour and the Liberal Democrats perceived the past state of the British economy under the Tory government more negatively than they had prior to casting their ballot in the 1997 election. Similarly, we posit that Labour supporters would view the future state of the national economy under Labour more positively than they had before the election. This indicates that, contrary to many assumptions in the economic voting literature, voting behavior influences evaluations of the economy as voters seek to reduce inconsistencies between their vote choice and evaluations of the economy by bringing their attitudes in line with the vote they cast in the election. It also means that voters' post-election economic perceptions are, at least in part, influenced by and thus endogenous to their vote choice. This finding has two major implications: First, cross-sectional models of economic voting are likely to overestimate the effect of economic perceptions on the vote. Second, the endogeneity of economic perceptions may compromise the quality of economic voting as a mechanism for democratic accountability.
\end{abstract}


Although it is widely assumed that economic perceptions influence political behavior, the question of what shapes these perceptions in the first place has received only limited attention from political scientists. ${ }^{1}$ Instead, the small number of studies of people's macro-economic evaluations have focused mainly on the link between personal economic well-being and evaluations of the national economy (Conover, Feldman, and Knight 1986, 1987; Funk and García-Monet 1997), as well as how this link may be mediated by exposure to mass media or reference group comparisons (Mutz 1994; Mutz and Mondak 1997). In addition, scholars have started to investigate several other variables that contribute to heterogeneity in people's economic evaluations. This literature has shown that people's perceptions of the macro-economy are frequently biased and vary systematically with people's economic self-interest, the information they seek out or receive about the economy, and how they make sense of this information (Alt 1991; Duch, Palmer, and Anderson 2000; Haller and Norpoth 1997; Hetherington 1996; Krause 1997).

What remains underdeveloped in the literature are systematic accounts of the political biases that help shape people's views of the performance of the macro-economy. In this paper, we examine one such bias-the act of voting for a new government-in detail. Drawing on psychological theories of attitude formation, which hold that behavior can affect attitudes and that people strive to maintain consistency across their behaviors and cognitions, we argue that casting a ballot for a new government skews people's perceptions of the economy in particular and predictable ways. Specifically, we posit that people's evaluations of the macroeconomy are malleable and will be systematically biased in favor of the party people voted for in the previous election.

We test this argument with the help of panel surveys collected before and after the 1997 British general election, which allow us to track the extent to which people's assessments of the macroeconomy change as a function of their vote. We find that voters who rejected the incumbent Tories became significantly more likely to say that the economy had performed badly in the previous year. Moreover, those who had voted for the new governing party (Labour) developed more positive expectations about the economy's future performance than they had forecast prior to the election. This result implies that, for those 
who participated in the election, economic evaluations collected in post-election surveys cease being exogenous to the choices they made on election day, thus calling into question the extent to which the economy truly moves voting behavior.

\section{How Voting Behavior Can Affect Economic Perceptions}

Since the early days of economic voting research, scholars have modeled the vote or government popularity as a function of either objective economic conditions or perceptions of those conditions (Nannestad and Paldam 1994). Most commonly, this is done with the help of aggregate data in a time-series design or cross-sectional individual-level data (for an overview, see Lewis-Beck and Paldam 2000). In recent years, researchers have made increasing use of perceptual measures of the economy to explain election outcomes and government approval. Regardless of the level of analysis, such a strategy assumes that perceptions of the economy are exogenous to the vote and that perceptions of the economy are relatively accurate reflections of the objective state of the economy (Anderson and O'Connor 2000). Yet, while there is a spirited debate about exactly how citizens reason about the economy, few students of political behavior have sought these fundamental assumptions underlying the relations among economic perceptions, objective economic conditions, and political behavior.

Below, we argue that assumptions of exogeneity and unbiasedness are likely to be problematic because of the possible consistency-inducing effect of vote choice on economic perceptions. In particular, we argue that models of voting behavior estimated with the help of economic perceptions collected in the same survey are likely to overstate the true effects of the economy. Moreover, because of this bias, models that make use of objective economic indicators are likely to misspecify the actual impact of the economy on

political support. In this study, we seek to pinpoint whether the political bias introduced in cross-sectional survey designs is more likely to stem from attitudes (such as partisanship) or behavior (such as vote choice). Most fundamentally, based on psychological theories of selective perception and cognitive consistency, we 
argue that it is just as likely that voting behavior influences economic perceptions as the other way around.

Theories of selective perception are based on the idea that people are motivated to maintain consistency in their beliefs and attitudes (Abelson 1968; Festinger 1957; McGuire 1968; Rosenberg 1956). ${ }^{2}$ Although a number of variations on the consistency theme have been proposed over the years, the central elements are essentially identical: people frequently experience inconsistencies among their cognitions (beliefs, attitudes, and values) or among their cognitions and behavior. These inconsistencies foster psychological discomfort, also known as cognitive dissonance, and people seek to reduce it by restoring consistency, either by changing their attitudes or by modifying their behavior (Festinger 1957). ${ }^{3}$

While most theories that link attitudes and behaviors assume that attitudes lead to actions (Fishbein and Ajzen 1975), a number of studies have shown that behaviors also can lead to changes in people's attitudes (Funder and Colvin 1991). In fact, the idea that behavior impacts on attitudes is the major theme of Bem's (1972) self-perception theory, "which argues that people often infer their attitudes from the evaluation implied by their recent or salient behaviors" (Eagly and Chaiken 1998, 278-9; Bem 1972). The evidence that behavior can influence attitudes has been found to be particularly strong when an action, such as a vote cast only every few years, cannot easily be undone (Harvey and Mills 1971). The act of deciding irrevocably between alternatives usually produces cognitive dissonance because the attractive aspects of the rejected alternative and the unattractive aspects of the chosen alternative are inconsistent with the choice. Following earlier research, we argue that cognitive consistency is useful for understanding the link between people's vote choices and politically-relevant perceptions (Regan and Kilduff 1988).

Cognitive consistency provides a robust mechanism for linking people's attitudes and behaviors, and people's drive for cognitive consistency is well documented in a variety of contexts. Yet, despite its robustness and the various insights into political attitudes and behavior it has generated, ${ }^{4}$ consistency theory has never been put to the test to explain people's perceptions of the economy. Mapping onto the theoretical constructs of consistency theory, we hypothesize that vote choice and macroeconomic perceptions are the respective action and attitude for which people will seek consistency. ${ }^{5}$ Because a cast ballot cannot be 
undone, people will restore consistency by bringing their attitudes-in this case, attitudes about past economic performance under the old government and expectations about future performance under the new government-in line with their vote choice. ${ }^{6}$

\section{Behavior Versus Attitudes: The Role of Partisanship as a Political Bias}

Naturally, the relationship between vote choice and economic perceptions we hypothesize is unlikely to exist in isolation of other factors-in particular, partisanship. In fact, because partisanship is related to vote choice and may be correlated with economic perceptions as well, the relationship between past vote and current economic evaluations may, in part, be spurious. That is, the correlation we may observe between the vote and economic perceptions may be due to the direct effect of partisanship on both variables. If this is the case, our argument could be weakened because people would not be reconciling their current attitudes (economic perceptions) to their previous behavior (vote choice) but to their long-held predispositions (partisanship).

Yet, while the link between partisanship and the vote is well-documented, there is mixed evidence that partisanship indeed directly affects economic perceptions. For example, Conover, Feldman, and Knight $(1986,1987)$ examined the impact of partisanship (identification with the presidential party) and evaluations of parties' competence to deal with the economy on voters' perceptions of inflation and unemployment rates. Although they found that the relationships were in the expected direction, the effects for partisanship did not reach conventional levels of statistical significance in either of their studies. Moreover, while the effects for party competence were statistically significant, they were substantively small.

In a related cross-national study of economic voting in Western Europe, Wlezien, Franklin, and Twiggs (1997) examined the effects of political attitudes-pre-election vote intention-on perceptions of economic performance. Consistent with expectations, they reported that evaluations of the macroeconomy were, at least in part, predicted by vote intention. However, the Wlezien et al. study did not examine the 
effects of partisanship on economic perceptions, nor is it clear precisely which attitudinal construct vote intention was supposed to measure. Moreover, in contrast to the Conover et al. studies and our own research design below, the Wlezien et al. study examined only the contemporaneous effects of pre-election vote intention on economic evaluations. Thus, the study did not examine the effects of partisanship, investigate whether attitudes and vote choice have differential effects on post-election economic perceptions, or examine the malleability of economic perceptions with the help of data collected at different points in time (see also Wilcox and Wlezien 1996). ${ }^{7}$

The most ambitious study linking partisanship and economic perception to date is Evans and Andersen's (2001) longitudinal study using panel data about political preferences and economic perceptions through a five-year electoral cycle (1992-97) in Britain. They find that controlling for 1992 party support considerably reduces the effects of concurrent retrospective sociotropic perceptions on party support in 1997. Moreover, a 5-wave model shows sociotropic perceptions to be both strongly conditioned by prior party support and to have almost no independent concurrent impact on incumbent party popularity in 1997 . Thus, Evans and Andersen's result also point toward the conclusion that economic perceptions are politically biased; like Conover et al., however, they also focus on the role of partisanship as the primary driver of this endogeneity.

When discussing their findings, Conover, Feldman, and Knight speak variously of political preconceptions (1986) and predispositions (1987) that may bias evaluations of the economy. Similarly, following the argument made by Campbell, Converse, Miller and Stokes (1960), Wlezien, Franklin, and Twiggs (1997) and Evans and Andersen (2001) call attention to the possible endogeneity of economic perceptions by reasoning that voters have a partisan "perceptual screen" that helps shape their attitudes about the economy. Clearly, these studies recognize and argue in favor of considering the political factors-that is, the potential endogeneity-that may underlie people's perceptions of the macro-economy. We agree with these insights but seek to further develop this line of research by arguing that attitudes, such as partisanship, may not be the only political factors that drive economic perceptions. We postulate that a more complete and 
dynamic theory of how political behavior and attitudes about the economy are linked should include the vote as a consistency-inducing mechanism as well. Establishing consistency implies changing some attitudes to bring them into line with behavior or other attitudes. This means that a more thorough examination of the effect of voting behavior and partisanship on economic attitudes requires the inclusion of attitudes and behavior in models of economic perceptions as well as data collected of the same individuals at different points in time (i.e., panel data).

Our study thus seeks to extend the existing literature, first, by providing a more comprehensive formulation and empirical account of the mechanisms underlying the influence of political variables on people's economic perceptions; second, by identifying a crucial and hitherto unexamined source of the potential endogeneity of economic perceptions-past vote-that potentially has broad applicability to other political attitudes; third, similar to Evans and Andersen (2001) by conceptualizing economic perceptions and economic voting as the result of an iterative (intertemporal) process of attitude formation resulting, in part, from past behavior, not simply from attitudes that are contemporaneously related; and fourth, by investigating one of the classic questions in the cognitive consistency literature-namely, whether it is attitudes (such as partisanship) or actions/behavior (vote) that have the greater consistency-inducing effect.

\section{Endogenous Economic Voting in the 1997 British Election}

Although some of the classic work linking the economy and government support has been conducted in the British context (Goodhart and Bhansali 1970; Alt 1978; Sanders 1991), economic voting is a comparatively new approach to explaining voter behavior in Britain compared to explanations focused on social-structural factors (e.g., Butler and Stokes 1969; Franklin 1992). In part, this is due to the fact that there has been a secular decline in the importance of social structure and party attachment as determinants of the vote (Butler and Kavanagh 1992; Crewe, Sarlvik, and Alt 1977; Franklin 1985). This has provided an opening for short-term influences and issue voting, in particular economic voting (Alvarez, Nagler, and 
Bowler 2000; Norris 1997; Sanders 1999a; Studlar, McAllister, and Ascui 1990): "In a period when classbased voting has declined and levels of partisan identification have fallen-implying a reduction in the size of the Downsian 'standing vote'-this sort of mechanism adds an important dimension to our understanding how the new, rational, 'consumer' voter behaves” (Sanders 1999a, 253).

However, the verdict as to the utility of the economic voting model in the British case is not unanimous (cf. Sanders 1996; Evans 1999; Pattie, Johnston, and Sanders 1999). In fact, contrary to the expectations of standard economic voting models, the 1997 election saw the end of almost two decades of rule by the Conservative Party and the ascent of "New" Labour despite a good economy (Gavin and Sanders 1997). ${ }^{8}$ And although the economy played a less prominent role in 1997 compared to other British elections, researchers have reported significant relationships between people's perceptions of economic well-being and their vote choice that were consistent with the economic voting model (Evans 1999; Sanders 1999a; Pattie, Johnston, and Sanders 1999). We argue below that these may be an artifact and that part of the reason for such relationships may lie in the consistency-inducing effect of people's own voting behavior.

\section{Hypotheses}

We expect voters' post-election perceptions of the economy to be influenced by, and thus to be endogenous to, their choice on election day. That is, in contrast to the vast majority of economic voting research, we hypothesize that the causal arrow between economic perceptions and the vote runs from vote choice to economic perceptions. Specifically, we expect that people's post-election evaluations of the economy's past and future performance will be adjusted to be more consistent with their vote choice. Depending on the political situation surrounding the election, we anticipate the following scenarios. Voters who re-elected an incumbent government can be expected to evaluate past and future performance of the national economy significantly more positively than those who did not, and also more positively than they themselves had indicated prior to the election. In contrast, in a contest such as the 1997 British election, 
where the Labour party replaced the Tories in government, voters who helped throw out the Tory government should develop more negative perceptions of economic performance during the reign of the previous administration than those who sought to re-elect the old government. In addition, we expect that those who voted for the new Labour government will develop systematically more positive expectations regarding the nation's future economic well-being. In the case of prospective opinions, this effect may be also be due to voters' expectations regarding economic management competence. Specifically, a vote for Labour coupled with a Labour win may well lead respondents to assume that their prospective opinion about the economy will improve since the party that Labour voters think is better at managing the economy won the election.

Hypothesis 1: Voters who cast a ballot for Labour or the Liberal Democrats are expected to develop more negative retrospective sociotropic economic perceptions than those who voted to re-elect the Tories.

Hypothesis 2: Voters who cast a ballot for Labour are expected to develop more positive prospective sociotropic economic perceptions than those who voted for the Tories or the Liberal Democrats.

Comparing the effects of vote choice on both retrospective and prospective perceptions provides an opportunity to examine the validity of the consistency thesis with regard to more than one attitude (i.e., retrospective and prospective perceptions). In addition, it allows us to compare the relative impact of voting behavior on different kinds of economic perceptions. We hypothesize that vote choice should affect prospective and retrospective evaluations to different degrees. Retrospective responses are, at least to some extent, anchored in reality-past economic performance has already happened and was observable. In contrast, prospective evaluations have to be formed about events that have not yet happened. As a consequence, beliefs about prospective economic conditions, much more than descriptions of past conditions, should be open to adjustments that would preserve cognitive consistency. Thus, the cognitive consistency mechanism should perform better with regard to a perception (future performance) that allows more variation in the operation of the mechanism than a perception that allows less variation (past performance). Hence,

Hypothesis 3: Vote choice is expected to have a stronger effect on prospective economic perceptions than retrospective ones. 


\section{Data and Measures}

The theoretical argument we make above suggests a relationship between vote choice for or against the new government and economic perceptions that is structured temporally and has a clearly identifiable cause and effect: we posit that respondents have economic perceptions at time $t_{1}$; vote at time $t_{2}$; and subsequently adjust their perceptions at time $t_{3}$. Testing this argument requires the use of panel surveys that measure economic perceptions before and after the election: before the election as a baseline against which the formation of post-election evaluations can be compared. Moreover, it requires that we measure vote choice after an election has just been held. Finally, such a set of surveys has to control for the influence of partisanship as a predisposition that may drive both the vote and economic perceptions.

Fortunately, a set of panel surveys collected in Great Britain before and after the 1997 general election fulfilled the requirements of our research design (Heath, Jowell, and Curtice 1999). ${ }^{9}$ The surveys we employ are part of a larger set of panels conducted from 1992 to 1997 . They were based on random national samples of British citizens and asked numerous questions concerning people's attitudes and voting behavior (Heath, Jowell, and Curtice 1999). Fieldwork for the first wave used here was conducted between October 10 and December 12, 1996; the data for the second wave used here were collected between May 2 and July $10,1997 . .^{10}$

\section{Dependent Variables}

The measures of retrospective and prospective sociotropic economic perceptions were based on the following questions: "Looking back over the past year or so, would you say that Britain's economy has got stronger, got weaker, or stayed the same?" and "Looking forward to the year ahead, do you think Britain's economy will get stronger, weaker, or stay about the same?" For our dependent variables, we employ the post-election measures. These variables were coded from 1 to 5 , with 5 indicating the most positive response (“a lot stronger") and 1 indicating the most negative response ("a lot weaker") (see Appendix A). 


\section{Independent Variables}

\section{Vote Choice}

Past vote was the variable designed to estimate the impact of the respondent's vote choice on economic perceptions and to test the predictions of the consistency argument. Our measures, collected in the post-election panel wave, were based on the question: "What party did you vote for in the general election?" Recall that the 1997 election brought an end to almost two decades of rule by the Conservatives who were replaced by a Labour government under Prime Minister Tony Blair, in part with significant help from Liberal Democratic voters. Past vote therefore was coded as two dummy variables where one variable was coded $1=$ vote for the Labour party (and 0 otherwise), and the other was coded $1=$ vote for the Liberal Democrats (and 0 otherwise). As a result, the category of comparison was vote for the Conservatives. ${ }^{11}$

\section{Pre-Election Economic Perceptions}

Because voters may not be randomly assigned to different categories of economic perceptions prior to the election, it may simply be the case that those who voted for Labour or the Liberals already had more negative evaluations prior to the election. To avoid the problem of non-random assignment to the various categories of the sociotropic economic perceptions variable prior to the election, it is important that we control for people's pre-election economic perceptions. The pre-election perception variables were coded identically to the dependent variables (on a 1-5 scale).

\section{Partisanship}

In addition to controlling for economic perceptions voters had before the election, we also sought to ensure that vote choice was not simply a proxy for the effect of partisanship. We therefore included two variables measuring people's party identification in the pre-election panel wave. Including partisanship ensures that the vote choice variable captures just the effect of having voted for the new government on economic perceptions. Partisanship was measured by asking respondents: "Generally speaking, do you think 
of yourself as Conservative, Labour, Liberal Democrat, or what?" We recoded this variable into two dummy variables $($ Labour $=1$; all others $=0$ and Liberals $=1$; all others $=0$ ) so that they would parallel the vote choice variable.

\section{Control Variables}

We also controlled for a number of variables that have been identified by past researchers as significant determinants of economic perceptions (Conover, Feldman, and Knight 1987; Duch, Palmer, and Anderson 2000). In addition, we included several variables that traditionally have been found to affect voting behavior in Britain (cf. Alvarez, Nagler, and Bowler 2000). These variables were measured in the postelection panel and include people's personal economic and employment situation, ${ }^{12}$ information about and interest in politics, ${ }^{13}$ social class, and relevant demographic variables (age, gender, income, education, region, union membership, and type of employment). ${ }^{14}$ Finally, we also controlled for whether respondents reported having voted $(=0)$ or not $(=1)$ in order to ensure that we properly attribute any effects for actually having voted Labour, Liberal, or Conservative.

\section{Analysis}

The dependent variables were 5-category measures, with the corresponding survey questions asking respondents to evaluate the state of the economy. Responses to these questions were coded so that they range from "a lot weaker" at the low end to "a lot stronger" at the high end. Given that this evaluation is an ordered categorical variable, an ordered maximum likelihood estimation technique such as ordered logit is a more appropriate econometric method than linear regression. ${ }^{15}$ Ordered logit, like linear regression, assumes a particular ordering of the responses along a single dimension. Unlike linear regression, however, it does not impose the assumption that all adjacent responses are equidistantly apart. ${ }^{16}$ 


\section{Vote Choice and Retrospective Economic Perceptions}

Table 1 shows the results for two models of retrospective sociotropic economic perceptions: one model includes only the major variables of theoretical interest: vote choice, partisanship, and pre-election perceptions; the other is the fully specified model that includes these three variables as well as all of the control variables. The results provide strong evidence for the endogeneity hypothesis in the case of retrospective perceptions: individuals who voted for Labour or the Liberal party developed significantly more negative perceptions of past economic performance after the election than those who did not. The results also show that the effects of a vote for Labour and the Liberals on sociotropic retrospective perceptions were both statistically and substantively significant and very similar across the two estimation models.

(Table 1 about here)

These effects are all the more remarkable given that we controlled for people's past economic perceptions, partisanship, and a number of important control variables, such as people's evaluations of their own economic situation. As expected, and similar to the vote choice variable, the coefficients for partisanship were negative; however, they failed to achieve conventional levels of statistical significance in both models and thus did not exert a significant independent effect on retrospective economic perceptions. Thus, consistent with the insignificant effects reported for partisanship by Conover et al., it appears that partisanship does not exert a strong effect on the formation of post-election economic perceptions. Instead, the major political mechanism underlying retrospective sociotropic economic assessments appears to be vote choice. Those who voted for Labour or the Liberals were more likely to develop negative retrospective perceptions of the economy under the Tories.

The highly significant results for the lagged sociotropic economic perceptions variable suggest that people's assessments of the economy were quite stable between the pre- and post-election panel waves. Moreover, and as expected, we found that people tended to judge the country's economic performance to a moderate degree with an eye toward their own personal economic well-being. However, beyond this 
egocentric effect, the coefficients for many of the other control variables turned out to be insignificant. The only exceptions were age and gender. Older respondents were more likely to say that the economy had been performing well, while women were significantly more likely to evaluate the nation's economic performance over the past year negatively. In fact, aside from the effect of past perceptions, the gender gap is among the most significant effects on evaluations of the economy over the past year.

\section{Vote Choice and Prospective Economic Perceptions}

When we examined the effect of vote choice on people's expectations of economic performance (prospective sociotropic perceptions), we found that the coefficient for Labour voters again achieved statistical significance in the expected direction. In line with the consistency thesis, respondents who voted for Labour developed much more positive assessments of the country's future economic performance than those who did not. In fact, the results were similar to those reported in the case of retrospective evaluations. Thus, contrary to our expectations, there was no obvious difference in the effects of the vote on prospective versus retrospective evaluations of the economy.

The results reported in Table 2 also show, however, that having voted for the Liberals did not translate into more optimistic assessments of economic performance under Labour. In fact, the results show that Liberals and others (including Conservatives), were not different from one another in their forecasts of the nation's economy under the new Labour government. This result makes sense insofar as the Liberals and the Conservatives now shared the opposition benches to the newly elected government under Tony Blair.

(Table 2 about here)

Looking at the effects of partisanship on people's economic expectations, we found that their coefficients were again larger than their standard errors. However, only Labour partisanship achieved conventional levels of statistical significance, and it did so only in Model 1, which included none of the control variables. Once we controlled for the effects of the other variables, the coefficient again failed to 
achieve statistical significance. These results thus mirrored those obtained in the earlier analyses of retrospective economic evaluations, suggesting that the effects of partisanship were small. In addition, lagged prospective evaluations turned out to be significant in the fully specified Model 2 as well. Thus, people's prospective judgments about the economy were relatively stable, though the effects appeared significantly smaller than in the case of retrospective judgments.

When we examined the control variables, we found that the results were similar to those obtained for retrospective perceptions. Thus, those who evaluated their personal economic situation positively were also more likely to view the nation's economic future positively, but this effect was statistically significant only when we employ a one-tailed test of significance. Moreover, except for the variable measuring public sector employment, none of the control variables were statistically significant at conventional levels. The coefficient for public sector employment showed a positive relationship, suggesting that respondents with jobs in the public sector had a more positive outlook of the country's economic situation.

\section{The Substantive Effects of Voting for Labour and Liberal Democrats}

Given that the marginal effects of regressors in ordered logit models are not equal to their coefficients, we illustrate the variables' substantive impact by calculating how respondents' economic evaluations vary with their vote choice for Labour. Using the ordered logit coefficients from Tables 1 and 2, we can characterize the magnitudes of the regressor's - that is, the vote's - estimated effects on evaluations of the national economy for typical respondents by calculating the probabilities of having positive economic perceptions for different sets of voters. ${ }^{17}$

The probabilities reveal that, after the election, Labour voters had a .34 probability of stating that national economic conditions were "a lot" or "a little" stronger today than a year ago. In contrast, those who did not vote for Labour had a .56 probability of saying the economic had gotten better. Similarly, while Liberal Democratic voters had a .33 probability of stating that national economic conditions were "a lot" or 
"a little" stronger today than a year ago, those who did not vote for the Liberals had a .50 probability of expressing this view. Thus, voting for Labour or the Liberals clearly engendered more negative retrospective evaluations of the economy. Regarding prospective evaluations, we find that Labour voters had a .57 probability of stating that national economic conditions would get "a lot" or "a little" stronger in the year ahead. In contrast, respondents who did not vote for Labour had only a .38 probability of saying that the country's economy would improve over the next year. Thus, the probability that a Labour voter would say that the economy would get stronger was 19 percentage points higher than that of a respondent who had not voted for Labour. Also, the probability that a Labour voter would have positive expectations of the nation's economy was 24 percent higher than the probability of having a positive view of the economy's performance under the Tory government. Thus, voting for the new Labour government produced systematically more positive expectations about the country's future economic performance. (Similar results obtain when we examine the probabilities of expressing a negative opinion).

\section{Discussion}

Our evidence from the 1997 British general election supports the contention that vote choice systematically affects the formation of economic perceptions, even when we control for economic perceptions people held prior to the election and for people's long-run political predispositions in the form of partisanship. Thus, the data supported our first two hypotheses: we find that a vote for Labour affected both retrospective and prospective evaluations such that casting a ballot for the newly elected Labour government subsequently produced more negative perceptions of how the economy was performing prior to the election under the Tories and more optimistic expectations about how it would perform in the future under Labour. Similarly, voting for the Liberal Democrats led to more negative assessments of the economy under the Tories, but did not have any effect on judgments about future economic performance under Labour.

Although we find clear evidence of a consistency effect, our expectation spelled out in Hypothesis 
3-namely that vote choice would have a stronger effect on prospective economic perceptions than retrospective ones-was not supported by the data. We speculate that prospections are more akin to guesses and, as such, simply have more random variation than perceptions of things that have already happened. As a result, significant relationships are more difficult to obtain. ${ }^{18}$

Our results can be challenged both on empirical and conceptual grounds. The validity of the inferences we draw can be challenged empirically if the post-election panel is no longer representative of the original sample from which it was drawn. This is possible because panel data are subject to attrition over successive panel waves and because multivariate models such as the ones presented here tend to reduce the number of cases due to non-responses to some questions. To examine whether the sample we used to estimate our models was in fact biased, we calculated the sample characteristics on the questions used in the analysis and compared them to those of the pre-election sample (see Appendix B). As it turns out, concerns about a biased sample are unfounded.

Moreover, while our results for economic prospections are robust, we cannot determine with certainty whether they are due to the consistency effect we hypothesize or the somewhat simpler mechanism of rational expectations resulting from voters' expectations regarding economic management competence. Specifically, a vote for Labour coupled with a Labour win may well lead respondents to assume that their prospective opinion about the economy will improve since the party that Labour voters think is better at managing the economy won the election. More research is needed to sort out the precise causal mechanisms that link vote choice and people's formations of economic expectations. What we can say, however, is that observationally, retrospections and prospections both react similarly to vote choice in the election.

Some might argue with the results we find for partisanship. While we find the hypothesized support for the consistency thesis, partisanship turns out to be insignificant. Thus, the evidence suggests that the consistency-inducing effect exists only for behavior (vote choice) but not for attitudes (partisanship). In this context, it is important to note, however, that partisanship and voting behavior are correlated. In our sample, for instance, the correlation between partisanship and vote choice was $\beta=.72(\mathrm{p}<.001)$ for Labour and $\beta=.48$ 
$(\mathrm{p}<.001)$ for Liberal Democrats. ${ }^{19}$ Thus, it is likely that, aside from having a direct effect on economic perceptions, partisanship also affects economic perceptions indirectly via the vote. ${ }^{20}$ Moreover, because partisanship is very stable, it cannot account, by definition, for changes in people's economic perceptions. ${ }^{21}$ As an aside, it is worth noting, as the research by Evans and Andersen (2001) suggests, that partisanship matters in the long term because it drives the vote. In the short term (right before and after an election), we find that the vote matters, possibly because it entails a more vivid experience. Either way, these insignificant effects for partisanship are compatible with evidence documenting a decline in the importance of partisanship. In the context of our study, this would suggest that the value of partisan attachment as a rationalization mechanism may have been reduced in recent years, while the importance of the vote may have increased at the same time. ${ }^{22}$

One might raise the question of whether our results could be replicated in other countries. We speculate that the strength of the relationships we identify may be influenced by a country's political context. For instance, the British electorate may be more polarized than other electorates, or British political parties may occupy more clearly defined positions in the political spectrum than parties in other countries (Budge 1999). As a result, voters may display greater levels of cognitive consistency and post-election adjustment in Britain than elsewhere. Given that the 1997 British election surveys are the only ones currently available that include all the necessary questions in both the pre- and post-election panel waves, these are not issues that we can address empirically. However, we would point out that the 1997 election was an exceptional contest because it was marked by less ideological and policy polarization between the two main parties than other elections since the 1960s (Budge 1999; Sanders 1999b; Webb and Farrell 1999). Thus, the results we obtain for 1997 are probably weaker than what they would have been in previous elections.

Similarly, we would argue that the findings we report here are probably understated in historical perspective, given that this contest was distinctive for being fought less on economic factors than on 'sleaze' and a general weariness with the Conservatives who had been in office since 1979. Since a campaign fought on economic performance might be expected to produce even stronger results than those reported here, we 
would argue that the circumstances surrounding the 1997 election in the UK actually provide particularly compelling evidence of the consistency effect.

The 1997 election, in which Labour won a large majority despite favorable economic indicators for the Conservative government, challenges the economic voting argument generally and its applicability to British elections in particular. In the relatively short history of economic voting studies, the UK has been one of the countries in which the economic voting model has held the greatest sway. While it is likely that there are several explanations for why the objective economy failed to save the Conservatives, our results support the contention that the impact of the subjective economy on the vote reported by researchers may be significantly overstated (Evans 1999). In fact, our results can be interpreted to suggest that, in an election when the objective economy could not account for the election outcome, a significant portion of the significant relationships between people's economic perceptions and the vote reported by researchers may be traced to the endogeneity of economic perceptions inherent in cross-sectional (post-election) survey data.

If people's perceptions of the economy are in part endogenous and systematically biased in favor of the wining party and against the losers, then cross-sectional models that use economic perceptions as an independent variable are likely to overestimate the economy's effect on the vote. Although this should be particularly true for analyses that employ data collected immediately after an election, even pre-election surveys are likely to retain some endogeneity as a result of the votes respondents cast in the previous election. Consequently, any analysis of economic voting using cross-sectional data is likely to show a stronger effect of economic assessments on the vote than the actual state of the economy would warrant. This will magnify the theoretical importance researchers accord the state of the economy in the calculus of voters.

\section{Conclusions}

Our finding that voters adjust their views of the state of the economy to be consistent with their vote choice poses a crucial challenge to widely-accepted assumptions, findings, and interpretations in the area of 
economic voting research, which claim that the state of the economy drives voters' choices. In contrast to this vast body of research, we find evidence that the causal arrow between economic perceptions and the vote may well run from vote choice to economic perceptions.

As such, our findings also add to the literature on cognitive consistency effects on political attitudes. It shows that economic perceptions, like perceptions of policy issues and political candidates for example, are sufficiently important to voters to warrant adjustment after the election. Perhaps more importantly, the findings presented here contribute to a growing branch of the economic voting literature, which seeks to identify the conditions under which people's perceptions of the economy mediate the link between the objective economy and their political behavior (Alt 1991). Our results indicate that people's economic evaluations are filtered through their past behavior and are, thus, at least partially disconnected from the objective economy. This suggests that people's past behavior may play just as critical a role in guiding evaluations of the economy as does their ability to accurately interpret objective economic conditions. In fact, how people voted in the last election may well influence their willingness to seek out accurate information about the state of the economy in the first place. Such findings highlight the importance of a research agenda that focuses on critically evaluating commonly-held assumptions underlying research on economic voting-in this case, the assumptions that economic perceptions actually are exogenous to the vote.

The findings we report here also have implications for standard practices in the area of economic voting research. The vast majority of individual-level economic voting studies employ cross-sectional data. Our results indicate that this may prove problematic because of the possible consistency-inducing effect of reported vote choice on economic perceptions. In particular, if there is a consistency-inducing effect, any cross-sectional model that explains voting behavior with the help of economic perceptions collected in the same survey is likely to overstate the true effects of the economy. Thus, whenever possible, it may be preferable to utilize panel surveys that would allow researchers to explain post-election vote choice with economic perceptions collected in a pre-election panel wave. Given that such data are frequently unavailable, it may behoove researchers to use statistical approaches (such as instrumental variable approaches) in order 
to deal with the potential endogeneity inherent in post-election economic perceptions.

Finally, our results hold important implications for democratic theory because they suggest that individuals do not judge the performance of the government exclusively with an eye toward the policies that are actually adopted and implemented. Instead, citizens' own actions also drive their judgments of macroeconomic performance. In the aggregate, this individual-level bias is liable to produce a systematic advantage for a new government. Take the British case as an example: the greater the number of voters who elected the new Labour government, the greater the number of citizens who hold negative perceptions of the economy under the Tories and positive expectations of future performance under Labour. This provides incumbents, such as the Labour party, with an opinion climate that can help stabilize public support in the short-term. Under these conditions, bad economic times may not hurt governments as much as is commonly assumed because those who cast winning ballots for Labour will look more negatively on the previous government's track record and will hold positive expectations regarding the current government's likely future performance.

This may create problems for the efficacy of economic voting as a mechanism of democratic accountability. After all, a fundamental tenet of democracy is that governments ought to be held responsible for their policies. Yet, people's tendency to maintain consistency between their previous behavior and current attitudes may serve to undermine this critical mechanism. In this context, the political opposition will face an uphill battle in trying to motivate voters to view a government's record objectively. In this way, accountability is compromised, not as a result of flaws in how political institutions are designed, but as a result of people's own internal drive for consistent behaviors and attitudes. In fact, the bias produced by the effect of past vote on current economic perceptions may in part explain why sometimes governments are retained in office despite poor economic performance.

To be sure, our results cannot directly account for such counterintuitive election outcomes as the 1992 and 1997 UK elections or the 2000 U.S. presidential contest, when objective economic conditions would have predicted the defeat of the eventual winner. However, they do indicate that in the 1992 election, for example, 
the results from the previous (1987) election and the recollection of past vote made it that much harder for Labour to win, even in circumstances of economic difficulty. Moreover, in both the 1997 UK election and the 2000 U.S. election there was less of a hurdle for a challenger to overcome, in terms of past vote gap. Thus, these results suggest that past voting decisions linger and have consequences that may affect the aggregate election outcome in years to come.

In addition, and aside from the lingering effects of past vote choice, our results suggest that significant effects of the subjective economy on the vote in elections where the objective economy does not appear to matter much may be overstated or, in part, be an artifact. Our evidence therefore challenges the dominant economic voting model and re-establishes the criticality of psychological mechanisms in political behavior, in contrast to the ever-growing influence of economic theories of politics.

We hasten to add that there may well be some potential benefits to the effects we identify. In particular, people's tendency to view their environment in ways that are consistent with their vote choice may hold the key to a stable government, at least during its initial phase in office (the so-called "honeymoon effect"). Voters' need for consistency is likely to insulate newly-elected governments from the immediate and unmitigated influence of a poor economy and give them the opportunity to implement policies before being judged again at the ballot box. We would argue that this is a benign consequence that provides voters with the necessary time to judge the true consequences of a government's policies. 


\section{Notes}

1. Much of the debate in the field of economic voting has centered around the question of which perceptions-sociotropic or egocentric, prospective or retrospective ones-are most predictive of government support or vote choice. For a recent overview of the literature, see Lewis-Beck and Paldam (2000).

2. Cognitive consistency theory has been applied in many areas and modified in as many different ways. It has also been referred to by different names, such as cognitive dissonance theory, and several theories of cognitions and behaviors-e.g., selective perception, projection-have been developed from it. For the sake of simplicity, we refer to these under the rubric of cognitive consistency here.

3. Individuals may, of course, choose to ignore inconsistencies. However, this has been found to be a less frequent occurrence than the attempt to restore consistency.

4. There is considerable support for the applicability of cognitive consistency and related theories to political behavior and attitudes (Krosnick 1990)-in particular, to the study of post-election attitudes (e.g., Beggan and Allison 1993; Frenkel and Doob 1976; Regan and Kilduff 1988; Stricker 1964).

5. Because sociotropic perceptions are the most consistent and powerful economic predictors of the vote (Fiorina 1978; Kinder and Kiewiet 1981; Lewis-Beck and Paldam 2000), and to establish the validity of our argument with regard to the most widely studied type of economic perception, we focus on the determinants of people's perceptions of the macroeconomy for the purposes of this study.

6. To be sure, dissonance-reducing behavior does not occur in all places or at all times. In fact, studies on selective perception (a phenomenon predicted by cognitive consistency theory) suggest that people may seek out contradictory information under certain conditions (Sears and Freedman 1967: 203). The studies that support cognitive dissonance theory use information that is closely tied to the decision (e.g., choice of information about cars after the purchase of a new car). Thus, perceptions become relevant if they can be shown to be related to behavior. Given that the economy is one of the most, if not the most, prominent, issues in most political campaigns, and given that a sizable literature shows economic perceptions to be related to voting behavior-particularly in the British case examined here-we argue that the sociotropic views of the economy are likely to be relevant to the choice voters make in an election.

7. The Wlezien et al. study assesses the effect of (pre-election) vote intention on economic perceptions using a simultaneous equation approach. The utility of this approach hinges on the assumption that there are truly exogenous variables that would allow for the models to be identified. That is, to be able to estimate such models using cross-sectional data, researchers have to determine a priori that there are variables that independently and exclusively determine political support and economic perceptions in order to parse out their respective independent effects. We argue that the existence of such exogenous variables is unlikely in any case, but especially because of the temporal nature of people's attitude formation processes. This rules out simultaneous equations or structural modeling as appropriate strategies for eliminating the reciprocity given that this estimation technique implies the existence of at least (and hopefully more than) one instrumental variable. It also rules out the use of cross-sectional survey data because it does not allow for a true test of exogeneity.

8. Most commentators attribute the Conservatives' defeat to several factors, most of which were unrelated to the country's economic performance at the time. These included internal divisions within the Conservative Party over European integration, the emergence of Tony Blair as a charismatic leader (the so-called "Blair factor"), accusations of sleaze, the Tories' mishandling of the ERM crisis (i.e., pulling the Pound out of the ERM), as well as a Tory-weary electorate (Denver 1998). And because the 1997 campaign was not primarily about the economy, the Conservatives did not benefit from a strengthening economy (Wickham-Jones 1997). As a result, voters did not exhibit much of a feel-good factor and (negative) subjective perceptions of the economy appeared to play a much stronger role in people's voting decisions than objective conditions in the country (Sanders 1999a; Wickham-Jones 1997). 
9. The 1992-1997 British Election Panel Survey contacted a random sample of registered British voters a total of eight times, the first wave being just after the April 1992 general election and the final wave just after the May 1997 general election. A wave of data collection was carried out each spring, immediately following the general elections (1992, 1997), local government elections (1993, 1995, 1996), and European Parliament elections (1994). In addition, there were two autumn waves, in 1995 and 1996, both following the party conference season. Of the original 3,534 completed interviews from the first wave in 1992, a total of 1,174 respondents were successfully re-interviewed in the fall of 1996, and 1,694 were successfully re-interviewed immediately after the 1997 election. Panel attrition was a major pre-occupation of the survey team (see Taylor, Heath and Lynn, 1996). Given that politics is not the most salient and relevant topic for the majority of the general population, political surveys frequently do not to achieve the highest of response rates. Furthermore, because about $10 \%$ of adults change their permanent address in any 12-month period, a considerable effort was needed to trace sample members to new addresses. Calculations of relevant sample characteristics (political information, social status, etc.) revealed no systematic differences between the original 1992 sample and the re-interviewed sample respondents, though the later samples had slightly higher levels of social status and information.

10. Some might argue that the time lapsed between the first and second wave is too long. While acknowledging that a first measure closer to the actual election would be desirable, we also wish to point out that it was well known at the time of the pre-election panel that the incumbent government would have to call an election very soon and that the election campaign was already well underway. Moreover, having a measure closer to the election should strengthen, not weaken, the relationship between variables measured in both panel waves. If we find evidence of the postulated relationships between the two waves, it would therefore be more likely to understate, not overstate, the existence and magnitude of the hypothesized effects. In any case, objective economic conditions did not change between the pre-election and post-election waves; in the quarters when panels were conducted, inflation was less than 1 percent, unemployment was between 7.7-7.9 percent, and the GDP growth rate was .9 percent (Source: International Financial Statistics of the International Monetary Fund). Thus, it is virtually impossible to attribute any changes in economic perceptions to changes in the objective economy.

11. The correlation between pre-election vote intention and post-election reported vote is $r=.698^{* * *}$. This means that, while most respondents' pre-election vote intention translated into an actual vote, the relationship is by no means perfect.

12. Given the frequently-cited influence of personal economic situation on sociotropic perceptions, we hypothesized that people's personal economic situation was related to their perceptions of the national economy. The personal economic situation variable measured people's financial situation and varied from the most negative evaluation (1) to the most positive one (5). Relatedly, we hypothesized that being unemployed was likely to have a negative effect on people's evaluations of the macroeconomy beyond the effect captured by the personal economic situation variable. The unemployment variable was a dummy variable, coded 0 or 1 (1=unemployed), and we expected a negative relationship between this variable and national economic perceptions.

13. We also sought to control for people's information about the political economy. First, we used a media exposure variable that asked people to report how frequently they read the newspaper $(1=$ do not read the paper; $5=$ every day; see Appendix A). Moreover, we included a measure of political interest to gauge how motivated people were to seek out information about politics. This question asked respondents to indicate how much interest they had in politics and ranged from "none at all" (1) to "a great deal" (5). We expected individuals with more information to be better informed about the objective state of the economy-that is, whether it was good or bad or could be expected to be good or bad in the future-and thus to be biased in the accurate direction (given Britain's economic situation at the time, in a positive direction). 
14. In addition, we included variables for levels of income (coded in categories from $1=$ low to $3=$ high), education (coded 1-7; high=7), class (coded 0-6; high=6), union membership ( 0,$1 ; 1=$ union member), and type of employment because these can be expected to contribute to biases in economic perceptions at the individual level as well (cf. Duch, Palmer, and Anderson 2000). Simply put, we expected individuals with high levels of education and income and those who indicated they belonged to the middle and upper classes to be somewhat sheltered from negative economic outcomes and thus, to be more likely to take a positive view of the country's economic situation. Similarly, we hypothesized that union members and those employed in the public sector (coded 0,$1 ; 1=$ public sector employee) would have more positive economic perceptions as these respondents are less likely to be laid off during difficult times. Regarding the age variable, we hypothesized that older respondents would have more positive perceptions as well, given that the mid-1990s were a time of economic upswing relative to the difficult times of the 1970s and periods during the 1980s. In addition, we expected women to have more negative economic perceptions as a result of their more precarious situation in the labor market. Finally, given the significant regional variation in economic performance in Britain, and given that, in 1997, the economic recovery was stronger in the South than in the North (Johnston et al. 2000)-we expected respondents in the South $(0,1$; $1=$ South) to have significantly more positive economic perceptions than respondents in the other regions (Curtice and Park 1999, McAllister and Studlar 1992). Taken together, this multivariate estimation model was designed to provide a stringent test for our central hypotheses concerning the consistency effect (for coding details, see Appendix A).

15. We chose to employ an ordered maximum likelihood procedure rather than ordinary least squares because of the possibility of uneven intervals between the categories of the dependent variable, which can lead to biased estimates. The choice of the proper ordered estimation method in part depends on our assumptions about the distribution in the population, not simply the sample. While probit assumes a normal distribution of the underlying latent variable, logit does not. The logistic distribution is quite similar to the normal, but with slightly heavier tails. Absent strong theoretical reasons for justifying one distribution over another, it is difficult for the purposes of our research in particular (and any political science research in general) to claim that one ordered procedure is superior to another. We used ordered logit, rather than probit, because there is little reason to assume that the two would yield different results, given that we cannot make strong distributional assumptions. As it turns out, when we estimated the models using probit, the results were essentially identical to those we obtained with logit.

16. As in the binomial logit model, the marginal effects of regressors on response probabilities are not equal to the ordered logit coefficients. Additionally, the marginal effects on the probabilities for mid-range responses (e.g., "same") do not necessarily have the same signs as the coefficients. If a regressor's coefficient is positive, an increase in that regressor always produces a decrease in the probability of the lowest response (e.g., "a lot weaker") and an increase in the probability of the highest response (e.g., "a lot stronger"). The directions of probability changes for mid-range responses, however, are ambiguous because they depend on the probability densities prior to the increase in the regressor.

17. The typical respondent's probabilities are calculated by holding all other variables at their average value. 18. We also wish to point out that the extent to which prospections are driven by the consistency effect, relative to a rational expectations effect that the economy will actually improve under Labour, was not a focus our analysis. To be sure, more research is needed to sort out these different effects.

19. Because partisanship and the vote are significantly correlated, we tested for the possibility that changes in economic perceptions were a function of changes in partisanship. Specifically, we re-analyzed the multivariate models with the help of a change in partisanship variable (-1 away from Labour, 0 no change; +1 toward Labour). The results showed that change in partisanship did not affect economic perceptions. For the sociotropic retrospective perceptions model (Table 1, Model 2), the coefficient for the change in partisanship variable was -.026 (std.error: .200,not significant); for the prospective model (Table 2, Model 2), the coefficient was -.371 (std.error:.225; not significant). In supplemental analyses, 
we also estimated the models reported in Tables 1 and 2 with the help of the post-election partisanship measure. As it turns out, the results are essentially identical to those reported there. Finally, when we include both partisanship variables in our estimations, both are statistically insignificant. These results are not at all surprising, given the stability in respondents' partisanship. Cross-tabulations revealed that only a small number of respondents changed their partisanship toward Labour from pre- to post-election panel (31 of 754 original panel respondents, or 4.1 percent).

20. Regardless of the precise causal forces at work, it is important to remember that correlations among our regressors-in particular between partisanship and vote choice-do not bias the coefficients we obtain but can make them less efficient. Thus, while it is possible that vote choice can affect partisanship or that partisanship would exert a stronger independent effect on economic perceptions if the correlation between partisanship and the vote was weaker, we would like to emphasize that this would not undermine the support for the endogeneity thesis reported here. If anything, lower correlations among the regressors would produce statistically more significant independent effects for both partisanship and vote choice.

21. When we re-estimated the models without partisanship variables, the results shown in Tables 1 and 2 were confirmed, and the coefficients for vote choice were virtually identical. The only difference was that a vote for the Liberal Democrats also had a positive and significant effect on prospective perceptions, though this effect was considerably smaller than the effect of a vote for Labour.

22. Given the debate over the applicability of the concept of partisanship to countries outside the United States, the meaning of the effects for partisanship is open to debate as well. However, because our study focused primarily on the effects of the vote on post-election economic perceptions, we would argue that these consistency effects we report are strong. Naturally, the generalizability of the consistency thesis will remain both an empirical and a conceptual question until further work has been conducted. 


\section{Appendix A. Variables and Question Wording}

Vote choice: "Which party did you vote for in the general election?"

Party Identification: "Generally speaking, do you think of yourself as Conservative, Labour, Liberal Democrat, or what?"

Sociotropic retrospective evaluations: “Looking back over the past year or so, would you say that Britain's economy has got stronger, got weaker, or stayed the same?" Got a lot weaker (1); got a little weaker (2); stayed the same (3); got a little stronger (4); got a lot stronger (5).

Sociotropic prospective evaluations: "And looking forward to the year ahead, do you think Britain's economy will get stronger, weaker, or stay about the same?" Get a lot weaker (1); get a little weaker (2); stayed the same (3); get a little stronger (4); get a lot stronger (5).

Egocentric retrospective evaluations: "In the past year, would you say that your household income kept up with prices?" Income was a lot lower than prices (1); income was a little lower than prices (2); income kept up with prices (3); income was a little higher than prices (4); income was much higher than prices (5).

Egocentric prospective evaluations: "Would you say that your household income will fall behind prices in the next year?" Income will be a lot lower than prices (1); income will be a little lower than prices (2); income will keep up with prices (3); income will be a little higher than prices (4); income will be much higher than prices (5).

Political interest: "How much interest do you generally have in what is going on in politics?" None at all (1); not very much (2); some (3); quite a lot (4); a great deal (5).

Media exposure: "About how often do you read the newspaper?" Do not read the paper (1); 1 day a week or less (2); 2-3 days a week (3); 4-5 days a week (4); every day (5).

Unemployment: Based on variable categorizing respondent's employment status. Unemployed=1; all others $=0$.

Income: "What is the total income of your household from all sources?" 15-category scale of annual income; Less than 3,999 (1); 38,000 or more (15). Recoded into three categories, ranging from 1 to 3.

Education: Coded 1-7, where 7 means higher level of education.

Age: "What was your age on your last birthday?" Actual age.

Sex: Female $=1$; male $=0$.

Union membership: Union member $=1$; others $=0$.

Public sector employment: Public sector worker $=1$; others $=0$.

Region (South): South=1; other region=0.

Class: "Based on skill, what would you say is your social class?" Never had a job (0); Unskilled worker (1); partly unskilled (2); skilled manual worker (3); skilled non-manual worker or military worker (4); managerial or technical worker (5); professional worker (6).

Nonvoter: Based on a question that elicited whether respondent voted in the last election. If no, coded $=1$; others $=0$. 
Appendix B. Descriptive Statistics

\begin{tabular}{|c|c|c|c|c|c|c|c|c|}
\hline \multirow[b]{2}{*}{ Variable } & \multicolumn{4}{|c|}{ Original Panel } & \multicolumn{4}{|c|}{ Sample Used in Estimations } \\
\hline & Mean & Std.Dev. & Min. & Max. & Mean & Std.Dev. & Min. & Max. \\
\hline $\begin{array}{l}\text { Retrospective sociotropic } \\
\text { economic perceptions }\end{array}$ & 3.404 & .896 & 1 & 5 & 3.426 & .883 & 1 & 5 \\
\hline $\begin{array}{l}\text { Prospective sociotropic } \\
\text { economic perceptions }\end{array}$ & 3.417 & .768 & 1 & 5 & 3.406 & .745 & 1 & 5 \\
\hline Vote choice (Labour) & .398 & .490 & 0 & 1 & .390 & .488 & 0 & 1 \\
\hline Vote choice (Liberal) & .156 & .363 & 0 & 1 & .185 & .389 & 0 & 1 \\
\hline Partisanship (Labour) & .402 & .491 & 0 & 1 & .410 & .492 & 0 & 1 \\
\hline Partisanship (Liberal) & .132 & .339 & 0 & 1 & .141 & .348 & 0 & 1 \\
\hline $\begin{array}{l}\text { Retrospective egocentric } \\
\text { economic perceptions }\end{array}$ & 2.690 & .904 & 1 & 5 & 2.685 & .866 & 1 & 5 \\
\hline $\begin{array}{l}\text { Prospective egocentric } \\
\text { economic perceptions }\end{array}$ & 2.813 & .766 & 1 & 5 & 2.858 & .779 & 1 & 5 \\
\hline Unemployment & .050 & .218 & 0 & 1 & .048 & .215 & 0 & 1 \\
\hline Political interest & 3.362 & .954 & 5 & & 3.396 & .926 & 5 & \\
\hline Media exposure & 3.462 & 1.799 & 1 & 5 & 3.381 & 1.762 & 1 & 5 \\
\hline Income & 1.993 & .806 & 1 & 3 & 2.024 & .787 & 1 & 3 \\
\hline Education & 3.408 & 2.092 & 1 & 7 & 3.998 & 2.069 & 1 & 7 \\
\hline Gender & .517 & .500 & 0 & 1 & .491 & .500 & 0 & 1 \\
\hline Age & 50.473 & 15.473 & 23 & 92 & 49.593 & 15.263 & 23 & 88 \\
\hline Union membership & .244 & .429 & 0 & 1 & .253 & .435 & 0 & 1 \\
\hline Public sector employment & .343 & .475 & 0 & 1 & .328 & .470 & 0 & 1 \\
\hline Region & .126 & .332 & 0 & 1 & .231 & .422 & 0 & 1 \\
\hline Class & 3.415 & 1.451 & 0 & 6 & 3.736 & 1.372 & 0 & 6 \\
\hline
\end{tabular}




\section{References}

Abelson, Robert P. 1968. Theories of Cognitive Consistency: A Sourcebook. Chicago: Rand McNally.

Alt, James. 1991. "Ambiguous Intervention: The Role of Government Action in Public Evaluations of the Economy," in Economics and Politics: The Calculus of Support ed. Helmut Norpoth, Michael S. Lewis-Beck, and Jean-Dominique Lafay. Ann Arbor, University of Michigan Press.

Alvarez, R. Michael, Jonathan Nagler, and Shaun Bowler. 2000. "Issues, Economics, and the Dynamics of Multiparty Elections: The British 1987 General Election." American Political Science Review 94 (1): 131-49.

Anderson, Christopher J., and Kathleen M. O'Connor. 2000. "System Change, Learning, and Public Opinion about the Economy." British Journal of Political Science 30 (1): 147-72.

Beggan, James K., and Scott T. Allison.1993. “The Landslide Victory That Wasn't: The Bias Toward Consistency in Recall of Election Support.” Journal of Applied Social Psychology 23 (8): 669-77.

Bem, D.J. 1972. "Self-Perception Theory." In L.Berkowitz (ed.), Advances in Experimental Social Psychology (vol.6, pp.1-62); New York: Academic Press.

Budge, Ian. 1999. "Party Policy and Ideology: Reversing the 1950s?" In Critical Elections: British Parties and Voters in Long-Term Perspective, ed. Geoffrey Evans and Pippa Norris. Thousand Oaks, CA: Sage.

Butler, David, and Dennis Kavanagh. 1992. The British General Election of 1992. London: Macmillan.

Butler, David, and Donald Stokes. 1969. Political Change in Britain. New York: St.Martin's Press.

Campbell, Angus, Philip Converse, Warren Miller, and Donald Stokes. 1960. The American Voter. New York: Wiley and Sons.

Conover, Pamela Johnston, Stanley Feldman, and Kathleen Knight. 1986. "Judging Inflation and Unemployment: The Origins of Retrospective Evaluations." Journal of Politics 48 (3): 565-88.

Conover, Pamela Johnston, Stanley Feldman, and Kathleen Knight. 1987. "The Personal and Political Underpinnings of Economic Forecasts.” American Journal of Political Science 31 (3): 559-83.

Crewe, Ivor, Bo Sarlvik, and James Alt. 1977. "Partisan Dealignment in Britain, 1964-1974.” British Journal of Political Science 7 (1): 129-90.

Curtice, John, and Alison Park. 1999. "Region: New Labour, New Geography?” In Critical Elections: British Parties and Voters in Long-Term Perspective, ed. Geoffrey Evans and Pippa Norris. Thousand Oaks, CA: Sage.

Denver, David. 1998. "The Government That Could Do No Right." In New Labour Triumphs: Britain at the Polls, ed. Anthony Heath. Chatham, NJ: Chatham House Publishers.

Duch, Raymond M., Harvey D. Palmer, and Christopher J. Anderson. 2000. "Heterogeneity in Perceptions of National Economic Conditions." American Journal of Political Science 44 (4): 635-52.

Eagly, Alice H., and Shelly Chaiken. 1998. "Attitude Structure and Function." In The Handbook of Social Psychology. Vol.1, $4^{\text {th }}$ ed., ed. Gilbert, Daniel T., Susan T. Fiske, and Gardner Lindzey. 269-322. New York: McGraw-Hill. 
Evans, Geoffrey. 1999. "Economic and Politics Revisited: Explaining the Decline in Conservative Support, 1992-95.” Political Studies 47 (1): 139-51.

Evans, Geoffrey, and Robert Andersen. 2001. "Endogenizing the Economy : Political Preferences and Economic Perceptions Across the Electoral Cycle." University of Oxford, CREST: Centre for Research into Elections and Social Trends Working Paper No.88, September 2001.

Festinger, Leon. 1957. A Theory of Cognitive Dissonance. Stanford, CA: Stanford University Press.

Fiorina, Morris. 1978. "Economic Retrospective Voting in American National Elections: A Micro-Analysis." American Journal of Political Science 22 (2): 426-43.

Fishbein, M., \& Ajzen, I. 1975. Belief, Attitude, Intention and Behavior: An Introduction to Theory and Research. Reading, MA: Addison-Wesley.

Franklin, Mark N. 1985. The Decline of Class Voting in Britain: Changes in the Basis of Electoral Choice, 1964-1983. Oxford: Clarendon Press.

Franklin, Mark N. 1992. "Britain." in Electoral Change: Responses to Evolving Social and Attitudinal Structures in Western Countries, ed. Mark N. Franklin, Thomas T. Mackie, and Henry Valen. New York: Cambridge University Press.

Frenkel, Oden, and Anthony Doob. 1976. "Postdecision Dissonance at the Polling Booth." Canadian Journal of Behavioral Science 8 (4): 347-50.

Funder, David C., and C. Randall Colvin. 1991. "Explorations in Behavioral Consistency: Properties of Persons, Situations, and Behaviors." Journal of Personality and Social Psychology 60 (5): 773-94.

Funk, Carolyn L. and Patricia A. García-Monet. 1997. "The Relationship Between Personal and National Concerns in Public Perceptions About the Economy." Political Research Quarterly 50 (2): 317-42.

Gavin, Neil T., and David Sanders. 1997. “The Economy and Voting." Parliamentary Affairs 50(4): 631-40.

Greene, William. 1997. Econometric Analysis, $3^{\text {rd }}$ ed. Upper Saddle River, NJ: Prentice Hall.

Haller, H. Brandon, and Helmut Norpoth. 1997. "Reality Bites: News Exposure and Economic Opinion." Public Opinion Quarterly 61 (4): 555-75.

Harvey, John, and Judson Mills. 1971. "Effect of a Difficult Opportunity to Revoke a Counterattitudinal Action Upon Attitude Change.” Journal of Personality and Social Psychology 18 (2): 201-09.

Heath, Anthony, R. Jowell, and John K.Curtice. 1999. British General Election Panel Survey, 1992-1997 [Computer File]. ICPSR Version. London, England: Social and Community Planning Research [producer], 1998. Colchester, England: ESRC Data Archive/Ann Arbor, MI: Inter-university Consortium for Political and Social Research [distributors].

Hetherington, Marc J. 1996. “The Media's Role in Forming Voters' National Economic Evaluations in 1992." American Journal of Political Science 40 (2): 372-95.

Johnston, Ron, Charles Pattie, Daniel Dorling, Iain MacAllister, Helena Tunstall, and David Rossiter. 2000. "Local Context, Retrospective Economic Evaluations, and Voting: The 1997 General Election in England and Wales." Political Behavior 22 (2): 121-43. 
Kinder, Donald R., and D. Roderick Kiewiet. 1981. "Sociotropic Politics: The American Case.” British Journal of Political Science 11 (1): 129-61.

Krause, George. 1997. "Voters, Information Heterogeneity, and the Dynamics of Aggregate Economic Expectations." American Journal of Political Science 41 (3): 1170-1200.

Krosnick, Jon A. 1990. "Government Policy and Citizen Passion: A Study of Issue Publics in Contemporary America.” Political Behavior 12 (1): 59-92.

Lewis-Beck Michael S., and Martin Paldam. 2000. "Economic Voting: An Introduction.” Electoral Studies 19 (2-3): 113-21.

McAllister, Ian, and Donley T. Studlar. 1992. "Region and Voting in Britain, 1979-87: Territorial Polarization or Artifact?" American Journal of Political Science 36 (1): 168-99.

McGuire, William J. 1968. "Theory of the Structure of Human Thought." In Theories of Cognitive Consistency: A Sourcebook, ed. Robert P. Abelson. Chicago: Rand McNally.

Mutz, Diana C. 1994. "Contextualizing Personal Experience: The Role of Mass Media." Journal of Politics 56 (3): 689-714.

Mutz, Diana C., and Jeffery J. Mondak. 1997. "Dimensions of Sociotropic Behavior: Group-Based Judgements of Fairness and Well-Being." American Journal of Political Science 41 (1): 284-308.

Nannestad, Peter, and Martin Paldam. 1994. "The VP-Function: A Survey of the Literature on Vote and Popularity Functions after 25 Years." Public Choice 79 (3-4): 213-45.

Norris, Pippa. 1997. Electoral Change in Britain Since 1945. Cambridge, MA: Blackwell Publishers.

Pattie, Charles, Ron Johnston, and David Sanders. 1999. “On Babies and Bathwater: A Comment on Evans' 'Economics and Politics Revisited'.” Political Studies 47 (4): 918-932.

Regan, Dennis T., and Martin Kilduff. 1988. "Optimism About Elections: Dissonance Reduction at the Ballot Box.” Political Psychology 9 (1): 101-07.

Rosenberg, Milton J. 1956. "Cognitive Structure and Attitudinal Affect." Journal of Abnormal Social Psychology 53 (4): 367-72.

Sanders, David. 1991. "Government Popularity and the Next General Election." Political Quarterly 62 (2): 235-61.

Sanders, David. 1993. "Why the Conservative Party Won Again,"in Britain at the Polls, 1992, ed. Anthony King. Chatham: Chatham House.

Sanders, David. 1996. "Economic Performance, Management Competence, and the Outcome of the Next General Election." Political Studies 44 (1): 203-31.

Sanders, David. 1999a. "Conservative Incompetence, Labour Responsibility, and the Feelgood Factor: Why the Economy Failed to Save the Conservatives in 1997." Electoral Studies 18 (2): 251-70.

Sanders, David. 1999b. “The Impact of Left-Right Ideology.”In Critical Elections: British Parties and Voters in Long-Term Perspective, ed. Geoffrey Evans and Pippa Norris. Thousand Oaks, CA: Sage. 
Sanders, David. 2000. "The Real Economy and the Perceived Economy in Popularity Functions: How Much Do Voters Need to Know? A Study of British Data, 1974-97." Electoral Studies 19 (2-3): 275-94.

Sears, David O., and Jonathan L. Freedman. 1967. "Selective Exposure to Information: A Critical Review." Public Opinion Quarterly 31 (2): 194-213.

Stricker, George. 1964. "The Operation of Cognitive Dissonance on Pre- and Post-Election Attitudes." Journal of Social Psychology 63 (1): 111-19.

Studlar, Donley T., Ian McAllister, and Alvaro Ascui. 1990. "Privatization and the British Electorate: Microeconomic Policies, Macroeconomic Evaluations, and Party Support." American Journal of Political Science 34 (4): 1077-101.

Taylor, Bridget, Anthony Heath, and Peter Lynn. 1996. The British Election Panel Survey 1992-95: Response Characteristics and Attrition. CREST Working Paper no.40. London and Oxford: CREST.

Webb, Paul, and David M. Farrell. 1999. "Party Members and Ideological Change." In Critical Elections: British Parties and Voters in Long-Term Perspective, ed. Geoffrey Evans and Pippa Norris. Thousand Oaks, CA: Sage.

Wickham-Jones, Mark. 1997. "How the Conservatives Lost the Economic Argument." In Labour's Landslide: The British General Election 1997, ed. Andrew Geddes and Jonathan Tonge. New York: Manchester University Press.

Wilcox, Nathaniel, T. and Christopher Wlezien, 1996. "The Contamination of Responses to Survey Items: Economic Perceptions and Political Judgements.” Political Analysis 5: 181-213.

Wlezien, Christopher, Mark Franklin, and Daniel Twiggs. 1997. "Economic Perceptions and Vote Choice: Disentangling the Endogeneity." Political Behavior 19 (1): 7-17. 
Table 1. Ordered Logit Models of Post-Election Retrospective Sociotropic Economic Perceptions

\section{Explanatory Variable}

Labour voter

( $1=$ Labour; $0=$ else $)$

Liberal voter

( $1=$ Liberal; $0=$ else $)$

Labour partisan

$(1=$ Labour; $0=$ else $)$

Liberal partisan

( $1=$ Liberal; $0=$ else $)$
Model 1

\section{$-.986 * * *$}

(.297)

$-.597 *$

(.305)

$-.358$

(.267)

$-.445$

$(.313)$

$1.002 * * *$

(.110)

$-.358$

$(.315)$
Model 2

$-.919 * *$

(.319)

$-.708 *$

(.324)

$-.212$

(.293)

$-.372$

$(.331)$

Pre-election retrospective

$.826 * * *$

sociotropic perceptions (high=positive)

(.121)

Nonvoter

.112

(1=did not vote)

(.344)

Retrospective egocentric perceptions

$.271^{*}$

(high=positive)

Unemployed

( $1=$ yes; $0=$ no)

Media exposure

(high=high exposure)

Political interest

(high=high interest)

Age

$.022 * *$

$(.008)$

Gender

$(1=$ female; $0=$ male $)$

$-.651 * * *$

(.196)

Income

.082

(high=high income)

Education

.059

(high=high education)

Class

(high=high social class)

South

.316

( $1=$ South; $0=$ other $)$

(.224)

Union membership

.030

( $1=$ union member; $0=$ other)

Public sector employment

$-.062$

( $1=$ public sector employee)

$\mu_{1}$

$-1.865$

$-.106$

(.782)

$\mu_{2}$

$-.102$

1.886

(.393)

(.737)

$\mu_{3}$

2.572

4.618

(.410)

(.765)

$\mu_{4}$

5.174

7.354

(.460)

(.816)

$\chi^{2}$ statistic of overall model fit:

$165.45^{* * *}$

$186.02 * * *$

Log likelihood:

$-552.54$

$-487.57$

Pseudo $\mathrm{R}^{2}$ :

.13

$\mathrm{N}$ :

500

.16

454

Notes: Standard errors in parentheses; The dependent variable contains five categories ranging from "a lot weaker" to "a lot stronger" to the question about the national economic situation over the last year. $* * *: p<.001 ; * *: p<.01 ; *: p<.05$ (two-tailed). 
Table 2. Ordered Logit Models of Post-Election Prospective Sociotropic Economic Perceptions

\section{Explanatory Variable}

Labour voter

( $1=$ Labour; $0=$ else $)$

Liberal voter

(1=Liberal; $0=$ else $)$

Labour partisan

( $1=$ Labour; $0=$ else $)$

Liberal partisan

( $1=$ Liberal; $0=$ else $)$

Pre-election prospective

sociotropic perceptions (high=positive)

Nonvoter

(1=did not vote)
Model 1

$.747 *$

(.308)

.109

(.317)

$.616^{*}$

(.279)

.485

(.333)

.164

(.121)

.341

(.340)
Model 2

$.774^{*}$

(.330)

.356

(.339)

.497

(.303)

.456

$(.353)$

.384

(.386)

Prospective egocentric perceptions

.246

(high=positive)

Unemployed

( $1=$ yes; $0=$ no)

Media exposure

.048

(high=high exposure)

Political interest

(high=high interest)

Age

Gender

$(1=$ female; $0=$ male $)$

Income

$-.065$

(high=high income)

Education

(high=high education)

$(.063)$

Class

(high=high social class)

South

( $1=$ South; $0=$ other $)$

( $1=$ union member; $0=$ other)

.507 *

(.243)

(1=public sector employee)

$-3.370$

$-1.263$

(.850)

1.445

(.849)

1.417

4.569

4.484

(.882)

$\chi^{2}$ statistic of overall model fit:

Log likelihood:

Pseudo R ${ }^{2}$ :

$\mathrm{N}$ :

(.521)

$52.65 * * *$

$-427.98$

.06

409

Notes: Standard errors in parentheses; the dependent variable contains five categories ranging from "a lot weaker" to "a lot stronger" to the question about the national economic situation over the next year. ${ }^{* * *}: \mathrm{p}<.001 ; * *: \mathrm{p}<.01 ; *: \mathrm{p}<.05$ (two-tailed). 